\title{
Tratamento de resíduos orgânicos provenientes de restaurante universitário: decomposição biológica monitorada
}

Treatment of organic waste from university restaurant: biological decomposition monitored

Jacson Rodrigues França, Alexandre Couto Rodrigues, Carlos Eduardo Balestrin Flores, Rafael Borth, GuiIherme Barros, Pablo Piceti Pretto, Willian Fernando de Borba, Pedro Daniel da Cunha Kemerich.

Laboratório de Planejamento e Monitoramento Ambiental - LPMA/UFSM,

Curso de Engenharia Ambiental da Universidade Federal de Santa Maria - UFSM/CESNORS

\section{Resumo}

$\mathrm{Na}$ atualidade, cada vez mais se torna evidente a necessidade de se dar uma destinação final ambientalmente adequada aos resíduos sólidos orgânicos, uma vez que estes são a maior parte do lixo produzido pelo homem, e sendo dispostos no meio ambiente de maneira incorreta, podem gerar inúmeros problemas, como a contaminação de solo e água, a lixiviação de nutrientes e a emissão de gases poluentes. Este trabalho tem por objetivo avaliar a eficiência da compostagem no tratamento de resíduos orgânicos resultantes das refeições do Restaurante Universitário da Universidade Federal de Santa Maria no campus de Frederico Westphalen, analisar os macro e micro nutrientes presentes no composto, presença ou ausência de parâmetros indesejáveis, bem como identificar as diferentes fases da compostagem de acordo com as variações de temperatura medidas no decorrer do processo. Ao final do experimento, pode-se observar que a técnica de compostagem foi eficiente, gerando um composto que pode ser útil na produção de alimentos.

Palavras-chave: Composto, leiras, compostagem, fertilizantes orgânicos.

\begin{abstract}
Nowadays, increasingly becomes evident the need to take a final destination environmentally sound waste organic solids, since these are most of the waste produced by man, and being discharged into the environment incorrectly, can generate numerous problems such as contamination of soil and water, nutrient leaching and greenhouse gas emissions. This study aims to evaluate the efficiency of composting organic waste treatment resulting from restaurant meals Federal University of Santa Maria campus in Frederico Westphalen, analyze the macro and micro nutrients present in the compound, the presence or absence of undesirable parameters, and identifying the different stages of composting according to the temperature variation measured in the process. At the end of the experiment, it can be seen that the composting technique was effective, yielding a compound that may be useful in the production of food.
\end{abstract}

Keywords: Compost piles, compost, organic fertilizers. 


\section{INTRODUÇÃO}

A quantidade de resíduos sólidos gerados nas últimas três décadas tem aumentado substancialmente, fato que desencadeia sérios danos para a população e para o meio ambiente (KEFALAS et al., 2011). Com essa preocupação, surgiram atualmente legislações que buscam uma gestão ordenada desses resíduos, tais como a Lei Federal $n^{\circ} 12305 / 2010$ que estipula a Política Nacional dos Resíduos Sólidos, buscando uma destinação e uma disposição final ambientalmente adequada a esses rejeitos.

No Brasil estima-se que $60 \%$ do lixo gerado é de origem orgânica (CNUMAD, 1992), e muitas vezes não passa por um processo adequado de destinação, o que acarreta a transmissão de organismos patógenos e doenças. Uma forma para tratamento dos restos orgânicos, bastante utilizada, é a compostagem, que consiste em um processo natural de decomposição dos resíduos orgânicos por microrganismos que, pela oxidação biológica dos materiais, liberam dióxido de carbono e água, resultando num composto rico em macro e micronutrientes úteis as plantas (KEFALAS et al., 2011).

A opção por priorizar reduções globais dos níveis de lixo requer permanente busca de alternativas tecnológicas, para que sejam aperfeiçoadas as técnicas mais adequadas ao tratamento de resíduos sólidos, conduzindo, portanto, a uma elevação do grau de recuperação de materiais e sua reintrodução no processo produtivo (reciclagem) (BLUNDI \& CAMPOS 1999).

A compostagem poderia ser utilizada como alternativa para transformação dos resíduos orgânicos sólidos, integrada num sistema de reciclagem de materiais ou como único sistema de tratamento da fração orgânica dos resíduos (Russo, 2003). Para que se tenha êxito no sucesso deste processo, é necessário um amplo trabalho de conscientização ambiental que vise à separação adequada dos resíduos, que acarreta em ganhos sociais, econômicos e ambientais para a sociedade (ALBUQUERQUE et al., 2009).

A temperatura é um fator indicativo do equilíbrio biológico, de fácil monitoramento que reflete a eficiência do processo. A compostagem ocorre tanto em temperatura termofílica ( $45 \mathrm{a}$ $\left.85^{\circ} \mathrm{C}\right)$ como mesofílica $\left(25 \mathrm{a} 43^{\circ} \mathrm{C}\right)$ (KIEHL, 1998). Alguns pesquisadores observaram uma temperatura ótima para máxima ação dos microrganismos até $60^{\circ} \mathrm{C}$ e que apesar de valores acima eliminar patógenos, o calor limita as populações havendo um decréscimo da atividade biológica (FERNANDES \& SILVA, 1996).

Justifica-se a importância deste trabalho como forma de fazer o uso da compostagem como uma alternativa de tratamento dos resíduos orgânicos provenientes de restaurante universitário.

O presente trabalho tem por objetivo avaliar o processo de compostagem de resíduos orgânicos de restaurante universitário através do acompanhamento de variações de temperatura, parâmetros indesejáveis, e alguns nutrientes analisados em laboratório.

\section{MATERIAIS E MÉTODOS}

\section{I Caracterização do local e preparo das leiras}

O presente estudo foi realizado no campus da Universidade Federal de Santa Maria - UFSM na cidade de Frederico Westphalen - RS, localizada a uma latitude $27^{\circ} 21^{\prime} 33^{\prime \prime}$ S e a uma longitude $53^{\circ}$ $23^{\prime} 40$ " O e altitude de 566 metros. Sua população, de acordo com a estimativa para 2009 é de 28295 habitantes. O município possui uma área

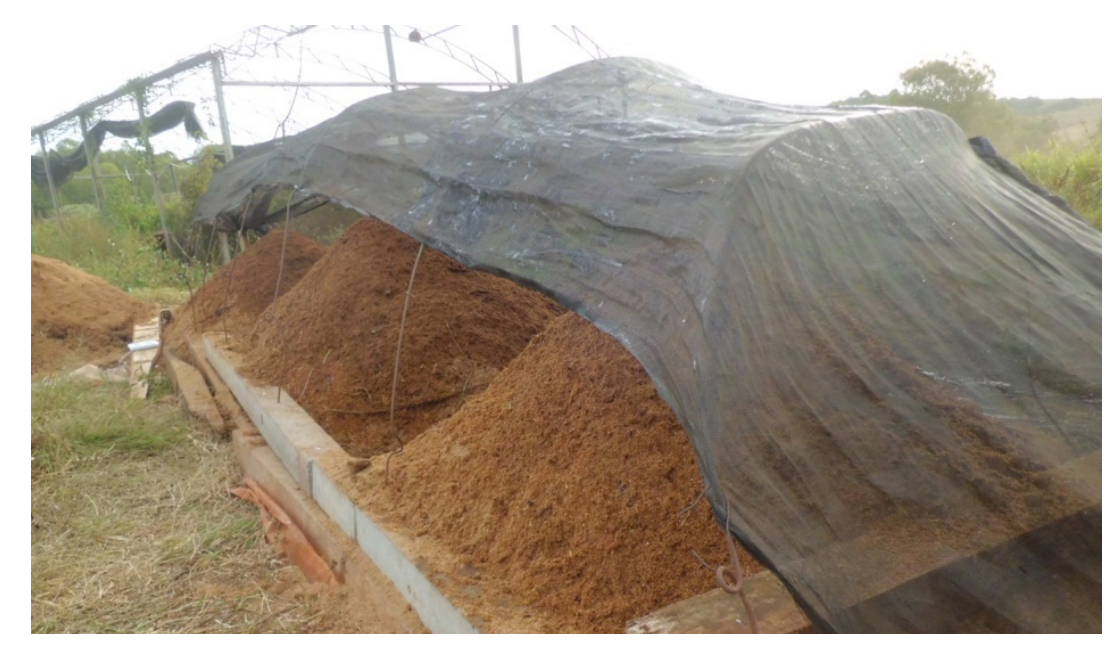

Figura 1. Leiras de Compostagem, Frederico Westphalen - RS, 2012. 
de $264,53 \mathrm{~km}^{2}$ (IBGE, 2010).

As 3 leiras de compostagem foram construídas com base de $1 \times 1 \mathrm{~m}$, com 1 metro de altura, conforme ilustra a figura 1. Para a compostagem foram utilizados restos de alimentos do Restaurante Universitário (RU) e serragem na proporção 15 $\mathrm{cm}$ de serragem para cada $5 \mathrm{~cm}$ de resíduo. Para evitar o contato direto da luz do sol, as leiras foram cobertas com sombrite. A manutenção da umidade foi mantida com auxílio de regadores e água sem cloro. $\mathrm{Na}$ base de cada leira foram colocadas lonas para evitar a contaminação do solo pelo lixiviado produzido no processo.

As temperaturas eram lidas com auxílio de um termômetro de álcool, realizando as leituras semanalmente sempre pela mesma pessoa para evitar distorções nos resultados. As leituras eram realizadas a 30,60 e $90 \mathrm{~cm}$ do solo, nas profundidades horizontais de 20 e $40 \mathrm{~cm}$. Para acelerar o processo, as leiras eram reviradas em intervalos de 15 dias, aumentando a aeração e consequente diminuição das condições de anaerobiose.

\section{RESULTADOS E DISCUSSÕES}

De acordo com o Anexo I da Instrução Normativa $\mathrm{n}^{\circ} 25$, (MAPA 2009) o composto produzido enquadra-se na classe "C", uma vez que o fertilizante orgânico, em sua produção, utiliza qualquer quantidade de matéria-prima oriunda de lixo domiciliar, resultando em produto de utilização segura na agricultura.

\section{I Temperatura}

A temperatura é um fator importante no processo de compostagem, podendo influenciar na qualidade final do composto formado. A temperatura é um fator indicativo do equilíbrio biológico, sendo de fácil monitoramento e refletindo na eficiência do processo. A compostagem ocorre tanto em temperatura termofílica $\left(45\right.$ a $\left.85^{\circ} \mathrm{C}\right)$ como mesofílica $\left(25\right.$ a $\left.43^{\circ} \mathrm{C}\right)$ (KIEHL, 1998). As variações de temperatura nas leiras estão apresentadas nas figuras $2 \mathrm{a}$ (leira 1), $2 \mathrm{~b}$ (leira 2) e 2c (leira 3). A primeira fase começa instantes após
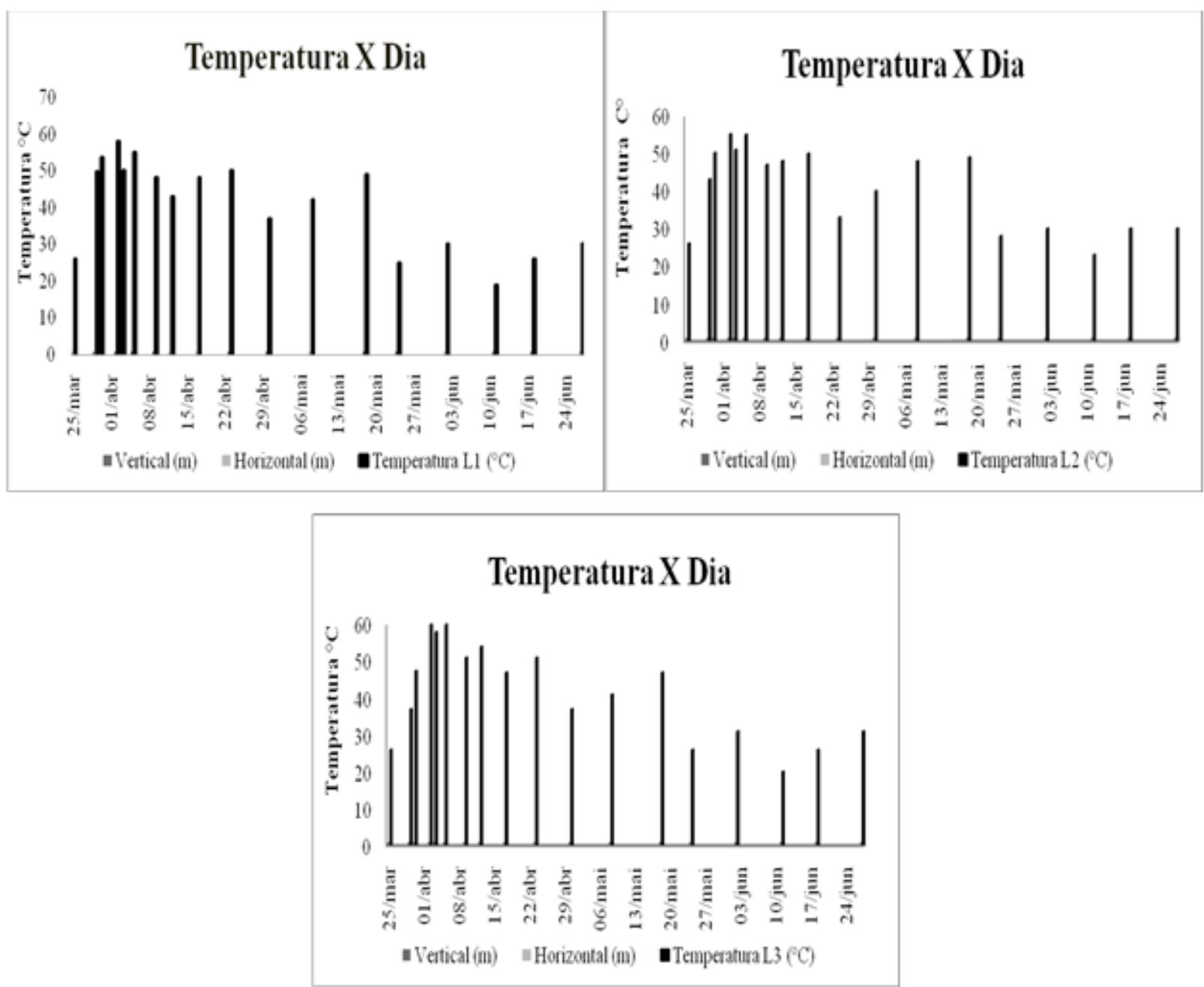

Figura 2. Temperaturas das leiras 1(a), 2 (b) e 3 (c), Frederico Westphalen-RS, 2012. 
a montagem da leira, quando os microrganismos começam a se desenvolver, sendo conhecida como mesófila, onde as temperaturas logo começam a aumentar. As leiras aumentam a temperatura nas suas três primeiras semanas atingindo até $55,2^{\circ} \mathrm{C}$ caracterizando a fase termófila. Após isto entra na terceira fase, conhecida como segunda fase mesófila que segundo KIEHL (1985) acontece o período de bioestabilização dos compostos.

As três leiras apresentaram um grande aumento na temperatura nos primeiros dias, KIEHL (1985) explica que coincidente com a acentuada perda de nitrogênio ocorrida nesta fase, seguida de temperaturas menores, mesmo após os revolvimentos; este fato pode ser atribuído à perda de $\mathrm{N}$ no início do processo, em consequência do metabolismo acelerado dos microrganismos, aproveitando todo o $\mathrm{C}$ para incorporar o nitrogênio disponível já no início da compostagem.

A primeira leira, figura 2 (a), apresenta as menores temperaturas durante o processo, o que permitiu trocas térmicas entre a leira e o ambiente, o que prejudica uma elevação da temperatura. A maior temperatura registrada foi de $58,1^{\circ} \mathrm{C}$ no dia 2 de abril no oitavo dia após a construção da leira.

A segunda leira apresentou valores de temperaturas intermediários, figura $2(b)$, não sendo os menores valores, devido a menor passagem do vento, por estar protegida entre as outras, e nem apresentou as maiores temperaturas, devido ao acúmulo de água em sua base devido ao desnível apresentado no terreno, o que pode gerar uma decomposição aneróbia, diminuindo as temperaturas. A maior temperatura registrada foi de $55,2^{\circ} \mathrm{C}$ no dia 2 de abril no oitavo dia após a construção da leira.

$\mathrm{Na}$ terceira leira a maior temperatura registrada foi de $62,4{ }^{\circ} \mathrm{C}$ no dia 2 de abril, provavelmente por esta leira ter encontrado as melhores condições ambientes para o desenvolvimento dos microrganismos decompositores, fazendo com que essa tenha sido a leira que apresentou a maior temperatura.

FERNANDES \& SILVA (1996) dizem que a elevação da temperatura seja necessária e interessante para a eliminação de microrganismos patogênicos, alguns pesquisadores observaram que a ação dos microrganismos sobre a matéria orgânica aumenta com a elevação da temperatura até $65^{\circ} \mathrm{C}$ e que acima deste valor o calor limita as populações aptas, havendo um decréscimo da atividade biológica.

Com a passagem de aproximadamente 90 dias é percebido que o composto não encontra-se totalmente humificado, confirmando que o mesmo ainda não atingiu a última fase da compostagem.

A última fase da compostagem é a de maturação ou cura, que segundo KIEHL (1998), é o estágio final da degradação quando o composto adquire as propriedades e aspectos desejáveis. $\mathrm{O}$ autor ainda diz que a compostagem pode levar até 120 dias quando o composto já passou por todos os processos e esta pronto para ser utilizado como adubação, aumentando a fertilidade do solo.

SCHLEGELMILCH et al. (2005) também relatam que aconcentração crítica de odores desagradáveis durante o processo de compostagem está principalmente nas primeiras 2 a 3 semanas.

\subsection{Parâmetros indesejáveis}

Durante o acompanhamento do processo de compostagem foram registradas a presença ou ausência de parâmetros indesejáveis, sendo observados no quadro 1.

Conforme NAKAGAWA (1992), o excesso de água (encharcamento) conjugado ao tipo de material utilizado na confecção das leiras causa a formação de odores, atraindo moscas.

A atividade microbiana de decomposição termina por gerar grande calor e elevação da temperatura interna da leira. A não adoção destas práticas resulta no aparecimento de larvas de moscas (Musca Domestica-Mosca Doméstica e Crysomya Chochiliomya - Mosca Varejeira) que se favorecem do ambiente de alta concentração de nutrientes dos restos de comida e cama com fezes das cobaias. Estas larvas, uma vez desenvolvidas, produzem antibióticos que inibem a atividade microbiana, estagnando o processo de compostagem.

\subsection{Macro e micro nutrientes}

As amostras foram coletadas através da técnica de quarteamento, e acondicionadas em sacos de amostragem devidamente identificados. Após isso foram encaminhadas para o Laboratório Laboratório de Análise do Solo da UFSM (Universidade Federal de Santa Maria- Campus Sede), e para o Laboratório de Química da UFPel (Universidade Federal de Pelotas), para análise de nutrientes (macro e micro) e relação $\mathrm{C} / \mathrm{N}$ respectivamente. A tabela 1 apresenta os resultados obtidos nas análises dos nutrientes.

De acordo com os limites estabelecidos pela instrução Normativa $n^{\circ} 23$ o elemento cálcio (Ca) apresenta valor abaixo dos valores mínimos exigidos, sendo que o elemento possui valor mínimo de $10 \mathrm{~g} \mathrm{~kg}^{-1}$. 
Quadro 1: Relação de presença e ausência de moscas, chorume, larvas e odor nas leiras.

\begin{tabular}{|c|c|c|c|c|c|c|c|}
\hline \multicolumn{4}{|c|}{ MOSCAS NAS LEIRAS DE COMPOSTAGEM } & \multicolumn{4}{|c|}{ CHORUME NAS LEIRAS DE COMPOSTAGEM } \\
\hline DATA & LEIRA 1 & LEIRA 2 & LEIRA3 & DATA & LEIRA 1 & LEIRA 2 & LEIRA3 \\
\hline $29 / 3 / 2012$ & Ausência & Ausência & Ausência & $29 / 3 / 2012$ & Ausência & Ausência & Ausência \\
\hline $30 / 3 / 2012$ & Presença & Ausência & Ausência & $30 / 3 / 2012$ & Ausência & Ausência & Ausência \\
\hline $2 / 4 / 2012$ & Presença & Presença & Presença & $2 / 4 / 2012$ & Presença & Ausência & Ausência \\
\hline $3 / 4 / 2012$ & Presença & Presença & Presença & $3 / 4 / 2012$ & Presença & Presença & Ausência \\
\hline $5 / 4 / 2012$ & Presença & Presença & Presença & $5 / 4 / 2012$ & Presença & Presença & Presenca \\
\hline $9 / 4 / 2012$ & Ausência & Ausência & Ausência & $9 / 4 / 2012$ & Presenca & Presenca & Presenca \\
\hline 9/4/2012 & \multicolumn{3}{|c|}{ REVOLVIMENTO } & 9/4/2012 & \multicolumn{3}{|c|}{ REVOLVIMENTO } \\
\hline $12 / 4 / 2012$ & Ausência & Ausência & Presença & $12 / 4 / 2012$ & Ausência & Ausência & Ausência \\
\hline $20 / 4 / 2012$ & Presenca & Presenca & Presenca & $20 / 4 / 2012$ & Presenca & Presenca & Presenca \\
\hline $20 / 4 / 2012$ & \multicolumn{3}{|c|}{ REVOLVIMENTO } & $20 / 4 / 2012$ & \multicolumn{3}{|c|}{ REVOLVIMENTO } \\
\hline $23 / 4 / 2012$ & Presença & Presença & Presença & $23 / 4 / 2012$ & Ausência & Ausência & Presença \\
\hline $30 / 4 / 2012$ & Ausência & Ausência & Ausência & $30 / 4 / 2012$ & Ausência & Presença & Presença \\
\hline $10 / 5 / 2012$ & Ausência & Ausência & Ausência & $10 / 5 / 2012$ & Ausência & Ausência & Ausência \\
\hline $10 / 5 / 2012$ & \multicolumn{3}{|c|}{ REVOLVIMENTO } & $10 / 5 / 2012$ & \multicolumn{3}{|c|}{ REVOLVIMENTO } \\
\hline $13 / 5 / 2012$ & Ausência & Ausência & Presença & $13 / 5 / 2012$ & Ausência & Ausência & Ausência \\
\hline $15 / 5 / 2012$ & Ausência & Ausência & Ausência & $15 / 5 / 2012$ & Ausência & Ausência & Ausência \\
\hline $20 / 5 / 2012$ & Ausência & Ausência & Ausência & $20 / 5 / 2012$ & Ausência & Ausência & Ausência \\
\hline $22 / 5 / 2012$ & Ausência & Ausência & Ausência & $22 / 5 / 2012$ & Ausência & Ausência & ncia \\
\hline
\end{tabular}

\begin{tabular}{|c|c|c|c|c|c|c|c|}
\hline \multicolumn{2}{|c|}{ ODOR NAS LEIRAS DE COMPOSTGEM } & \multicolumn{3}{c|}{ LARVAS NAS LEIRAS DE COMPOSTAGEM } \\
\hline DATA & LEIRA 1 & LEIRA 2 & LEIRA3 & DATA & LEIRA 1 & LEIRA 2 & LEIRA3 \\
\hline $29 / 3 / 2012$ & Ausência & Ausência & Ausência & $29 / 3 / 2012$ & Ausência & Ausência & Ausência \\
\hline $30 / 3 / 2012$ & Ausência & Ausência & Ausência & $30 / 3 / 2012$ & Ausência & Presença & Ausência \\
\hline $2 / 4 / 2012$ & Presença & Ausência & Ausência & $2 / 4 / 2012$ & Ausência & Presença & Ausência \\
\hline $3 / 4 / 2012$ & Presença & Presença & Presença & $3 / 4 / 2012$ & Ausência & Presença & Ausência \\
\hline $5 / 4 / 2012$ & Presença & Presença & Presença & $5 / 4 / 2012$ & Presença & Presença & Presença \\
\hline $9 / 4 / 2012$ & Presenca & Presenca & Presenca & $9 / 4 / 2012$ & Presenca & Presenca & Presenca \\
\hline 9/4/2012 & \multicolumn{3}{|c|}{ REVOLVIMENTO } & $9 / 4 / 2012$ & \multicolumn{2}{|c|}{ REVOLVIMENTO } \\
\hline $12 / 4 / 2012$ & Presença & Presença & Presença & $12 / 4 / 2012$ & Ausência & Ausência & Ausência \\
\hline $20 / 4 / 2012$ & Presenca & Presenca & Presenca & $20 / 4 / 2012$ & Presenca & Presenca & Presenca \\
\hline $20 / 4 / 2012$ & \multicolumn{3}{|c|}{ REVOLVIMENTO } & $20 / 4 / 2012$ & \multicolumn{2}{|c|}{ REVOLVIMENTO } \\
\hline $23 / 4 / 2012$ & Presença & Presença & Presença & $23 / 4 / 2012$ & Ausência & Ausência & Ausência \\
\hline $30 / 4 / 2012$ & Presença & Presença & Ausência & $30 / 4 / 2012$ & Ausência & Presença & Presença \\
\hline $10 / 5 / 2012$ & Ausência & Ausência & Ausência & $10 / 5 / 2012$ & Ausência & Presença & Presenca \\
\hline $10 / 5 / 2012$ & \multicolumn{3}{|c|}{ REVOLVIMENTO } & $10 / 5 / 2012$ & \multicolumn{2}{|c|}{ REVOLVIMENTO } \\
\hline $13 / 5 / 2012$ & Ausência & Ausência & Ausência & $13 / 5 / 2012$ & Ausência & Ausência & Ausência \\
\hline $15 / 5 / 2012$ & Ausência & Ausência & Ausência & $15 / 5 / 2012$ & Ausência & Ausência & Ausência \\
\hline $20 / 5 / 2012$ & Ausência & Ausência & Ausência & $20 / 5 / 2012$ & Ausência & Ausência & Ausência \\
\hline $22 / 5 / 2012$ & Ausência & Ausência & Ausência & $22 / 5 / 2012$ & Ausência & Ausência & Ausência \\
\hline
\end{tabular}

Tabela 1. Concentração de nutrientes presentes nas amostras. 
Tabela 1. Concentração de nutrientes presentes nas amostras.

\begin{tabular}{ccc}
\hline Parâmetros avaliados & Unidade & $\begin{array}{c}\text { Valores Médios das } \\
\text { amostras }\end{array}$ \\
Boro & $\mathrm{mg} / \mathrm{L}$ & 0,4 \\
Cálcio & $\mathrm{g} / \mathrm{kg}$ & 399,73 \\
Cobre & $\mathrm{mg} / \mathrm{L}$ & 0,89 \\
$\mathrm{CTC}_{\text {potencial }}$ & $\mathrm{mmolc} / \mathrm{kg}$ & 8,1 \\
Fósforo & $\mathrm{mg} / \mathrm{L}$ & 76 \\
Magnésio & $\mathrm{cmol}_{\mathrm{c}} \mathrm{L}$ & 1,084 \\
Matéria orgânica & $\%$ & 22,3 \\
Nitrogênio & $\mathrm{g} / \mathrm{kg}$ & 16,32 \\
pH água $(1: 1)$ & - & 6,5 \\
Potássio & $\mathrm{mg} / \mathrm{L}$ & 368 \\
Relação C/N & - & 24 \\
Cálcio & $\mathrm{cmol} / \mathrm{L}$ & 4,336 \\
Zinco & $\mathrm{mg} / \mathrm{L}$ & 16,39 \\
& &
\end{tabular}

De acordo com PAIXÃO et al. (2012) o $\mathrm{pH}$ (potencial hidrogeniônico) do composto pode ser indicativo do estado de compostagem dos resíduos orgânicos, caracterizando-o em ácido, básico ou neutro. Durante as primeiras horas de compostagem, o $\mathrm{pH}$ decresce até valores de, aproximadamente, 5 (de caráter acido), e posteriormente, aumenta gradualmente com a evolução do processo de compostagem e estabilização do composto, alcançando, finalmente, valores entre 7 e 8 (de caráter neutro a básico). Assim, valores baixos de $\mathrm{pH}$ são indicativos de falta de maturação devido à curta duração do processo ou à ocorrência de processos anaeróbios no interior da pilha em compostagem.

Para os teores de cálcio e magnésio os valores encontrados nas análises encontram-se bastante abaixo dos valores encontrados por BRITO (2008), que encontrou médias de 7,2 e 3,4 respectivamente. Diferente do que acontece para o elemento potássio, uma vez que esse autor encontrou médias de $0,94 \mathrm{cmol}_{\mathrm{c}} / \mathrm{dm}^{3}$, resultado muito semelhante ao deste trabalho.

Ao comparar com RIBEIRO et al. (2011) em compostagem de diferentes materiais orgânicos, percebe-se que os níveis de Cobre encontram-se abaixo da média encontrada pelos mesmos $(0,0038$ $\left.\mathrm{g} \mathrm{kg}^{-1}\right)$. Resultados semelhantes se obtiveram para o elemento Zinco e Boro, uma vez que os mesmos autores encontraram uma média de 0,0254 e 0,0374 $\mathrm{g} \mathrm{kg}^{-1}$ respectivamente.

\section{CONCLUSÃO}

A compostagem se mostrou uma técnica eficiente no tratamento de resíduos sólidos orgânicos de Restaurante Universitário, uma vez que transformou um passivo ambiental em um composto dotado de valor econômico e útil na fertilização do solo.

Através da aplicação do processo de compostagem em restos de alimentos foram foi obtido produto orgânico estável, que pode ser utilizado na adubação orgânica. Para que esse processo ocorra corretamente são necessários vários cuidados, assim evitando alguns fatores indesejáveis, como apresentados no trabalho.

\section{REFERÊNCIAS}

AGENDA 21. Conferência das Nações Unidas sobre Meio Ambiente e Desenvolvimento. Rio de Janeiro, 1992. Disponível em: http://www.mma.gov.br Acessado em 10 de Junho de 2012.

ALBUQUERQUE, T. C. S. de; SOUSA, R. C. P.; FIGUEIREDO, C. L. S.; COSTA, S. D. O. c. In: CONGRESSO BRASILEIRO DE RESÍDUOS ORGÂNICOS, 1, 2009. Anais eletrônicos. Vitória ES: Incaper, 2009. Disponível em: <http://www.fundagres.org.br/biossolido/icbro/cbro/Artigos/COMPOSTAGEM/Compostagem $\% 20$ de $\% 20$ residuos $\% 20$ organicos $\% 20$ gerados $\% 20$ na $\% 20$ Embrapa $\% 20$ Roraima.pdf>. Acessado em: 20 de Junho de 2012. 
BLUNDI, C. E.; CAMPOS, A. L. O.: Monitoramento de leira de compostagem de resíduos sólidos urbanos através de parâmetros específicos. $20^{\circ}$ CONGRESSO BRASILEIRO DE ENGENHARIA SANITÁRIA E AMBIENTAL, Rio de Janeiro 19999.

BRASIL. Instituto Brasileiro de Geografia e Estatística - IBGE. Contagem da População. 2009 Disponível em: < http://www.ibge.gov.br $>$. Acesso em: 21 Junho 2012.

BRASIL. Lei ${ }^{\circ} 12.305$, de 2 de agosto de 2010. Brasília, DF: [s.n], 2010. Disponível em: <http://www. planalto.gov.br/ccivil_03/_ato2007-2010/2010/lei/ 112305.htm>. Acesso em: 18 de Junho 2012.

BRASIL. Ministério da Agricultura, Pecuária e Abastecimento. Instrução Normativa $\mathrm{N}^{\circ} 25$, de 23 de julho de 2009, Brasília, 2009.

BRITO, M. J. C. Processo de compostagem de resíduos urbanos em pequena escala e potencial de utilização do composto como substrato. Dissertação (Mestrado em Engenharia de Processos) - Engenharia de Processos, Universidade Tiradentes, Aracajú, SE, 2008. 124 p.

FERNANDES, F.; SILVA, S. M. C. P. Manual prático para a compostagem de biossólidos, PROSAB - programa de Pesquisa em saneamento Básico UEL,Universidade Estadual de Londrina. Paraná, 1996. p.91.

IBGE, Município de Frederico Westphalen, RS, Senso 2010. Disponível em: http://www.ibge.gov.br/ cidadesat/topwindow.htm?1. Acessado em: 23 de Junho 2012.

INÁCIO, C. de T.; BETTIO, D. B.; MILLER, P. R. M.: O papel da compostagem de resíduos orgânicos urbanos na mitigação de emissão de metano. Embrapa Solos, Documento127, Rio de Janeiro. 2010.

KEFALAS, H. C.; SOUZA, S. A. D.; DENEKA, L. G.: Resíduos orgânicos na zona costeira: a proposta da compostagem. Simpósio Brasileiro de Oceanografia, Santos. Anais. Oceanografia e Políticas Públicas. 2011.

KIEHL, E. J. Manual de compostagem: Maturação e qualidade do composto. Piracicaba. Ed. Degaspari, 1998, 171p.
KIEHL, E. J. Fertilizantes Orgânicos. São Paulo, Ceres, 1985. p492.

MARAGNO, E.S. O uso da serragem em sistema de minicompostagem. 2005. 87f. Monografia

(Especialização em Gestão de recursos Naturais)Universidade do Extremo sul Catarinense, Criciúma.

MARAGNO, E. S; O Uso Da Serragem em Sistema de Minicompostagem. Monografia (Especialização em Gestão de recursos Naturais) Universidade do Extremo Sul Catarinense- UNESC. Criciúma, Outubro 2005. 66p. Disponível em <http://www.bib. unesc.net/biblioteca/sumario/000028/00002840. pdf $>$. Acessado em 26 de Junho de 2012.

NAKAGAWA, J. Compostagem: obtenção e uso. ENCONTRO SOBRE MATÉRIA ORGÂNICA DO SOLO: PROBLEMAS E SOLUÇÕES, 1, 1992, Botucatu. Anais. Botucatu: Champion Papel e Celulose Ltda., 1992. 29p.

NOGUERA, J. O.C; Compostagem. Influencia na Teoria Zeri, na Sustentabilidade Global e na Redução da Poluição Urbana. 8p. Disponível em http:// www.ipcp.org.br/References/ seAlimentando/ Composteiras/compostagem $\% 20$ ajuda $\% 20 \mathrm{a} \% 20$ reduzir\%20impactos.pdf. Acessado em 26 de Junho de 2012.

PHILIPPI JUNIOR, A. Agenda 21 e resíduos sólidos. RESID'99 - SEMINÁRIO SOBRE RESÍDUOS SÓLIDOS. São Paulo: Associação Brasileira de Geologia de Engenharia. 1999. p.15-25.

REIS, M. F. P.; BIDONE, F. R. A.; GEHLING, G. R.: Produção de macro e micro nutrientes através da compostagem de resíduos orgânicos provenientes das podas urbanas codispostos com resíduos da ceasa e lodo de estação de tratamento de esgotos. XXVII CONGRESSO INTERAMERICANO DE ENGENHARIA SANITÁRIA E AMBIENTAL. 2000. Disponível em: <http://observatorioderesiduos.com.br/wp-content/uploads/2011/03/iii-070. pdf $>$. Acessado em 25 de Junho de 2012.

RIBEIRO P. H.; SILVA V.M.; RABELO A.F.; Teores de Zinco, Cobre, Boro, Ferro e Manganês Em Composto com Esterco Bovino e Compostos de Gliricídia e Capim Elefante. XV ENCONTRO LATINO AMERICANO DE INICIAÇÃO CIENTÍFICA E XI ENCONTRO LATINO AMERICANO DE PÓS-GRADUAÇÃO - Universidade do Vale do Paraíba, 
São José dos Campos. 2011.

RUSSO, M. A. T. Tratamento de resíduos sólidos. Universidade de Coimbra, Faculdade de Ciências e Tecnologia, Departamento de Engenharia Civil, Coimbra, 2003.

SCHLEGELMILCH, M. Odour control at biowaste composting facilities. Waste Management, v.25, p.917-27, 2005.

TEIXEIRA, L. B; GERMANO, V. L. C.; JUMIOR, J. F.: EMBRAPA. Processo de Compostagem, a Partir de Lixo Orgânico Urbano, em Leira Estática com Ventilação Natural. Belém. 2004. 